6 months $(\kappa=0.57-0.59)$. We observed some reactivity, or a difference in reported behaviour associated with diary completion. For example, participants assigned no diary reported an average increase of 5.2 more unprotected anal sex acts over consecutive 3-month periods than those assigned an active diary schedule $(p<0.01)$.

Conclusions This study suggests that sexual behaviour and substance use data collected from young MSM during 3-month retrospective surveys-an interval commonly used in sexual behaviour research - are largely adequate. Web-based diaries can be used for up to 6 months to gather detailed behavioural data, and may be more appropriate than retrospective surveys for counts of anal sex acts. Furthermore, our finding that diaries may be associated with lower levels of reported sexual behaviour suggests that web-based diaries may be useful as a behavioural intervention to prevent HIV/STI among young MSM.

\section{2-S3.05 STIS AND NEIGHBOURHOOD DRUG MARKETS: FIRST A FORAY INTO MEASUREMENT}

doi:10.1136/sextrans-2011-050109.83

${ }^{1} \mathrm{~J}$ Jennings, ${ }^{2} \mathrm{R}$ Taylor, 'D Furr-Holden, ' J Ellen. ' Johns Hopkins University, Baltimore, USA; ${ }^{2}$ Temple University, USA

Background Neighbourhoods with drug markets (as compared to those without) may be more likely to have a greater concentration of STI infected sex partners. The objectives of this study were to assess the reliability and validity of three measures of neighbourhood drug markets.

Methods Data were collected from a cross-sectional household study of English-speaking, sexually-active persons, 15-24 years of age $(n=568)$ residing in selected neighbourhoods $(n=63)$. Participants responded via ACASI to "In your neighbourhood, are there any places like a street corner, block, house, club, bar, or other place where drug activity, like people selling or buying drugs, happens?" Survey reports were aggregated to the neighbourhood level and coded to $>(\mathrm{vs}<) 50 \%$ of residents reporting yes. To supplement this measure, information was obtained from systematic social observations (SSOs) using a multi-item assessment tool. Multiple rater information on a block was aggregated to the greater value to generate one value for a block unit. Ratings were summed to create one continuous measure at the neighbourhood level. Additionally drug arrest data on drug manufacturing, distribution, or intent to distribute was measured as a count per neighbourhood. We conducted reliability analyses using intraclass correlations and inter rater reliabilities and convergent validity testing using Poisson and linear regression.

Results Within-neighbourhood respondent agreement on surveyreports of neighbourhood drug markets had a reliability 0.50 and an intra class correlation of $0.10(\mathrm{p}<0.001)$. Neighbourhood surveyreports were significantly associated with gonorrhoea counts (IRR) 3.05, $95 \mathrm{CI} \% 2.07$ to 4.51, $\mathrm{p}<0.001$ ) and socioeconomic status (SES) ( $B-1.74,95 \mathrm{CI} \%-2.54$ to $-0.93, \mathrm{p}<0.001)$. The SSO drug market inter rater reliability was significant and moderate at the block level (0.57, $\mathrm{p}<0.05)$ with a reliability of 0.88 . The SSO measure was not associated with gonorrhoea counts (IRR 1.18, 95 CI \% 0.94 to 1.49 , $\mathrm{p}=0.15)$ and was significantly associated with SES ( $\beta-0.65,95 \mathrm{CI} \%$ -0.99 to $-0.31, \mathrm{p}<0.000$ ). Drug arrest counts were significantly associated with gonorrhoea counts (IRR 1.01, $95 \mathrm{CI} \% 1.00$ to 1.01 , $\mathrm{p}=0.002)$ and SES $(\beta-0.01,95 \mathrm{CI} \%-0.02$ to $-0.01, \mathrm{p}<0.001)$.

Conclusions The results suggest that neighbourhood drug markets can be measured through the use of household survey-reports and drug arrest data; the use of SSOs was less clear. The mismatch of the drug market measures may have been due to differences between the measures in sensitivity and specificity.

\section{2-S3.06 AREA-BASED SOCIOECONOMIC MEASURES ASSOCIATED WITH FEMALE CHLAMYDIA AND GONORRHOEA, SAN FRANCISCO, 2009}

doi:10.1136/sextrans-2011-050109.84

${ }^{1} \mathrm{~K}$ Bernstein, ${ }^{2} \mathrm{~S}$ Goldring, ${ }^{1} \mathrm{~J}$ Marcus, ${ }^{1} \mathrm{~S}$ Philip. ${ }^{1}$ San Francisco Department of Public Health, San Francisco, USA; ${ }^{2}$ University of Pittsburgh, San Francisco, USA

Background STD risk is influenced by individual-, network-, and community-level factors. Most research on STD risk has focused on individual-level factors, while limited data are available on community-level influences. In an ecologic analysis, we examined census tract-level factors associated with rates of female chlamydia (CT) and gonorrhoea (GC) in San Francisco in 2009.

Methods All female CT and GC morbidity reported in 2009 to the San Francisco Department of Public Health was geocoded to census tract. Tract-specific disease rates per 100000 females were calculated using 2009 population estimates. We used US Census data to examine area-based socioeconomic measures (ABSMs), calculated as the proportions of each census tract that were: lead by a female head of household, vacant homes, owner-occupied homes, living in the same residence for $\geq 5$ years, persons living below poverty, households with $\geq 30 \%$ of income spent on rent, less than high school (HS) education, and receiving food stamps. We also examined the number of people per room in the residence and graffiti complaints per square mile. Poisson regression models were created to explore the relationship between ABSMs and tract-level CT and GC rates. ABSMs were categorised into quintiles, and RR were estimated that corresponded to the increase in CT or GC rate associated with a 1-quintile change in the ABSM.

Results A total of 3267 CT and 1466 GC cases were geocoded to one of the 176 census tracts in San Francisco. The proportions of tracts with vacant units $(R R=1.11, p<0.0001)$, with less than HS education $(R R=0.91, \quad p=0.0017)$, with female head of household $(R R=1.40, p<0.0001)$, living below poverty $(R R=1.14, p<0.0001)$, living in the same residence for $\geq 5$ years $(R R=0.92, p=0.0017)$, and receiving food stamps $(R R=1.25, p<0.0001)$ were independently associated with female CT rates. In the analysis of female GC rates, the proportions of tracts with female head of household $(R R=1.25$, $\mathrm{p}=0.0026)$, living below poverty $(\mathrm{R} R=1.36, \mathrm{p}-0.002)$, people residing per room $(R R=0.84, p=0.023)$, and receiving food stamps $(R R=1.77$, $\mathrm{p}<0.0001)$ were associated with disease rates see Abstract O2-S3.06 table 1.

Abstract 02-S3.06 Table 1 poisson regression models

Area-based socioeconomic measures and

\begin{tabular}{|c|c|c|}
\hline & $\begin{array}{l}\text { Chlamydia rates, } \\
\text { females } \\
\text { RR }(95 \% \text { CI) }\end{array}$ & $\begin{array}{l}\text { Gonorrhoea rates, } \\
\text { females } \\
\text { RR }(95 \% \text { CI) }\end{array}$ \\
\hline \multicolumn{3}{|l|}{ Economic deprivation } \\
\hline$\%$ Below poverty line & $1.14(1.08$ to 1.21$)$ & $1.36(1.16$ to 1.60$)$ \\
\hline $\begin{array}{l}\% \text { Households with }>=30 \% \text { of income } \\
\text { spent on rent }\end{array}$ & - & - \\
\hline \multicolumn{3}{|l|}{ Concentrated disadvantage } \\
\hline $\begin{array}{l}\% \text { Population } 25+\text { with }<12 \text { years of } \\
\text { education }\end{array}$ & $0.91(0.85$ to 0.96$)$ & - \\
\hline$\%$ Homes with $>1$ person per room & - & $0.84(0.72$ to 0.98$)$ \\
\hline$\%$ Receiving any food stamp benefits & $1.25(1.16$ to 1.35$)$ & 1.77 (1.41 to 2.22$)$ \\
\hline \multicolumn{3}{|l|}{ Neighbourhood stability and social cohesion } \\
\hline$\%$ Homes occupied by owner & - & - \\
\hline$\%$ Vacant homes & $1.11(1.06$ to 1.16$)$ & - \\
\hline$\%$ Female-headed households & 1.40 (1.31 to 1.49$)$ & 1.25 (1.08 to 1.45$)$ \\
\hline$\%$ Same residence for $>=5$ years & $0.92(0.87$ to 0.97$)$ & \\
\hline
\end{tabular}

-Removed from model ( $\mathrm{p}>0.05)$.

Note: Each Poisson regression model had the following dependent variable: 1) Chlamydia rates in females, 2) Gonorrhoea rates in females. Rate ratios (RR) represent the change in the STI rate associated with a quintile change in the predictor variable. 